\title{
How Triple Mutation of Coronavirus (SARS-CoV-2) Developed in India
}

\author{
Sheema Fatima Khan
}

\section{ABSTRACT}

The COVID-19 infection is caused by the virus SARS-CoV-2. It is a single stranded RNA virus hence has high mutation rate. In a populous country like India, it can find large number of hosts to infect and thus undergo strong mutation. The Indian variant B.1.617 undergone three mutation to form B.1.617.2 (double mutant) and B.1.617.3 (triple mutant). The variant B.1.617.2 is declared a Variant of Concern due to its increase transmissibility, immune escape, increase effect of infection. The variant is also suspected to reduce vaccine efficacy and efficiency. It also the cause of overwhelming second wave of coronavirus in India. This harmful variant has also spread to other countries such as UK and Australia. Such harmful mutations are a result of aiming for herd immunity naturally against the virus. This article aims to understand the triple mutation and cause of devastating COVID-19 wave in India. And analyze steps to prevent future outbreaks.

Submitted : May 26, 2021

Published : June17*, 2021

ISSN: $2593-8339$

DOI: 10.24018 / ejmed.2021.3.3.893

Sheema Fatima Khan

Shadan Institute of Medical Sciences,

Teaching Hospital \& Research Centre,

Hyderabad-86, Telangana India.

(e-mail: sheemafatimak@gmail.com)

*Corresponding Author

Keywords: B.1.617.1, B.1.617.2, B.1.617.3, Coronavirus, SARS-CoV-2, Variant of Concern, Variant of Interest.

\section{INTRODUCTION}

The Coronavirus pandemic also called COVID-19 pandemic cause by virus SARS-CoV-2 has had a global impact. It thought us that no matter the race, gender, or age it can affect anyone and anywhere. The novel coronavirus was first reported in China in November of 2019 through "mysterious surging cases of pneumonia". After about a year and half, the virus has been successfully controlled at its the place of origin by adopting appropriate, responsible, and timely healthy and safe practices. Although, it continues to produce devastating effect in many parts of the world. India is experiencing an overwhelming second wave of coronavirus that is crushing its health care system. Life is a dynamic process. Mutations occur in all living organisms. It is the need of the hour to control the situation in India effectively with novel methods and stop the spread of virus as it is leading to increase loss of lives and alarming development of powerful variants that is rendering the existing technology used against the virus.

\section{INDIAN POPULATION}

India has a population of about 1.39 billion as of Tuesday, May 4, 2021, according to the Worldometer elaboration of the latest United Nations data and it keep on increasing every second. The country has a geographical land area of approximately 2.97 million $\mathrm{km}^{2}$. Therefore, the population density of India amounts to 464 per $\mathrm{km}^{2}$ i.e., 464 people per $\mathrm{km}^{2}$.[1] With this estimation in mind, it is not hard to imagine how crowded and bustling the country is. Also, $35 \%$ of the population is urban whereas the rest $65 \%$ approximately comes under rural India.[1] These parameters of population density and population distribution are necessary for any country to track and take steps in a period which requires vaccinating threshold percentage of people, reduce contact and social distancing to contain the pandemic.

\section{III. $1^{\text {ST }}$ CORONAVIRUS WAVE}

The transmission of any infectious disease depends on several factors associated with the disease [2]. One key concept is epidemiological triad which consists of interaction of pathogen (infective agent), host and environment [3].

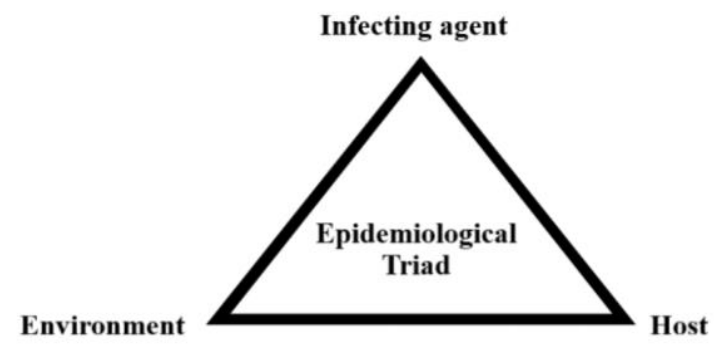

Fig. 1. Epidemiological Triad.

For host, it was seen that, India having largely young population with an average age of 28 years [1] gave the country a huge advantage over its 1 st wave of coronavirus wave. At that time, it predominantly had a severe effect on old population. Thus, the most severely affected countries in year 2020 were of aging population such as Italy, France and even UK and USA. Taking into account the agent, the initial variant was obviously less lethal and less transmissible than the current circulating strain. Finally, many studies for 
environmental factors such as temperature, humidity, wind speed, etc. done for COVID-19 infection found that season and temperature of Indian subcontinent had an impact on rate of transmission of virus. It was seen that temperature below $3{ }^{\circ} \mathrm{C}$, the number of COVID-19 infections in China is found to have a positive linear association with average temperature [2]. The psychology and response of people, during the early stages of pandemic in months of March till most of May, included scaling up public health, implementation of social distancing measures such as four stages of lockdown, restricted local movement, educational institutes and business were closed and were encouraged to implement distancelearning and work from home. Regulation and checks at international and domestic travel including negative RT-PCR report, thermal screening and 14 days institutional or home quarantine were made mandatory [4]. Yet, these measures were set up too little and too late compared to size of Indian economy and population. India lifted its lockdown when it was recording highest number of cases in the country [5]. The Dharavi Slums in Maharashtra shows best example of achieving herd immunity naturally. Due to its crowed condition, there was fast spread of COVID-19 and almost $57 \%$ of its population were already tested positive for antibodies against the virus [6]. India may have achieved herd immunity for initial stages of COVID-19 naturally [6].

The fact that even after strictest lockdown measures, unlocking stage witness record high number of infections. Thus, it indicated that lockdowns or shutdowns will not only fail to stop the epidemic but also severely impact the economy. This misinterpretation dissuaded India not to impose second national level lockdown for tsunami like second wave of Coronavirus.

\section{VIRUS AS A SPECIES}

The International Committee on Taxonomy of Viruses (ICTV) definition of virus is "A virus species is a polythetic class of viruses that constitutes a replicating lineage and occupies a particular ecological niche" [7], [8].

\section{A. Features of Virus}

Virus is a smallest living molecule consisting of single genetic material, either DNA or RNA. They lack enzymes for protein synthesis and hence are obligate intracellular parasites. Coronavirus belongs to Coronoaviridae family [9]. It has single stranded RNA as its genetic material, which is enclosed by Nucleocapsid, Envelop, Membrane and Spike. Spike protein is cleaved into two subunits, S1 and S2: The former contains the receptor binding domain (RBD), which enables the virus to attach to the angiotensin-converting enzyme 2 (ACE2) receptor on host cells [10].

\section{Mutations}

Mutation are the changes that takes place in the genetic sequence of all living organisms that helps them to evolve and adapt to the changing environment. Mutation includes insertions or deletions causing frameshift mutation, transversion or point mutation and recombination. Mutation can be deleterious or beneficial to the organism depending on the trait it offers for its survival. A phenomenon called natural selection is the selection of trait that help the organism to 'fit' better in environment. Those which do not possess these traits are eventually eliminated. A combination of the deletion and mutation in the spike protein conferred a selective advantage [11]. Similarly, the virus also undergoes mutation and natural selection which sometimes provides it with traits and properties such as more efficient viral replication, transmission, and evasion of host defense system which helps it to survive better in the environment [12]. When an endemic mutant virus spread to other part of the word by an infected host, for example via flights, the mutant virus starts spreading in other country. This process is called Founders effect.

Such high rates of mutation accumulate over period of time in immunodeficient or immunosuppressed patients who are chronically infected with SARS-CoV-2 which leads to viral evolution [13]. This is due to the fact that in chronic infection it allows adequate time for virus to be alive and undergo replication and mutation and therefore evolve [14]. These mutations are confirmed by the fact that such patients show reduced sensitivity to neutralizing antibodies when treated with convalescent plasma [11].

Around the world due to endemic mutation of virus, various 'variants' have emerged. The ones having suspicious harmful abilities are termed as variant of interest. Others having clear evidence to show its harmfulness are termed as Variant of Concern. The rapid surge of SARS-CoV-2 cases in months on January to February in UK caused by UK variant which is a Variant of Concern (VOC) 202012/01 and is also known as lineage B.1.1.7 or 20B/501Y.V1 (20). The Brazilian variant, P.1, also a variant of concern, is not only refractory to multiple neutralizing monoclonal antibodies but also more resistant to neutralization by convalescent plasma and vaccine sera [15]. Other Brazilian variants include B.1.135 and B.1.1.33 [16]. The Californian variants are B.1.427 and B.1.429 first identified in California in February 2021[17].

The Indian variant B.1.617.1 has undergone further mutations to form B.1.617.2 and B.1.617.3. Thus, the name triple mutation of Indian variant. B.1.617.2 (double mutant) is variant of concern whereas B.617.1 and B.1.617.3 are variant of interest.

TABLE I: MAJOR CONCERNING MUTATIONS OF SARS-COV-2 [18] Mutation Properties Viral lineage B.1.351, P.1,

E48K Immune escape B.1.617.1, B.1.617.2 B.1.617.3

B.1.1.7, B.1.351, P.1,

N501Y (NELLY) Higher Transmissibility B.1.617.1, B.1.617.2, B.1.617.3 B.1.1.7, P.1,

D614G (DOUG) Spike Protein changes $\quad$ B.1.617.1, B.1.617.2, B.1.617.3, B.1.351

\section{INDIA STILl HEADS FOR HERD IMMUNITY NATURALLY}

India has approximately 23 million cases and 254,000 deaths [19]-[21]. India has still vaccinated only $10 \%$ of its total population only $2 \%$ of the country has received both the doses of vaccines [22]. There are also doubts of underreporting of cases and deaths [23]. The positivity rate in India was $22.7 \%$, highest recorded on May 9 . As of May 24, it is down to about $15 \%$. Despite, extreme vaccines shortages the 
positivity rate of infection in India comes down, thus implying that India still heads for herd immunity naturally.

\section{Causes that Lead to Triple Mutation}

\section{A. Testing, Tracing, and Social Distancing Strategy Failure}

India has a population of 1.39 billion and population density of 464 people living per $\mathrm{km}^{2}$ area. Most Indians still follow traditional family culture and values and thus live in joint families with an average 10-16 people living in one house. This is true for both urban and rural population. Moreover, in rural and quite a few in urban India, many lack basic registration card called Adhaar card and other required documents. Hence a household has registered as well as unregistered people living together. Thus, the foremost step of testing fails here. Since, an unregistered person does not have details required by testing center, he/she may hesitate to go to testing center to get tested. Secondly the cost of testing is quite high compared to what a below average Indian earns. About $65 \%$ of Indian population is rural with most having profession related to agriculture whose earnings fluctuates frequently based on seasonal and marketing variations. There has been set up of free government testing centers. Despite that, lack of testing centers at accessible locations to all, also causes hesitance as it further adds to expenses due to additional travelling cost.

The tracing strategies also fails as India tests only about $6.5 \%$ of people per confirmed case. The WHO recommends 10-30 tests per confirmed case as a general benchmark of adequate testing [24]. Countries testing below the benchmark per confirmed case are likely to be testing inadequately and insufficiently to find all cases [24]. As crowded situation in India, social distancing strategy also fails. And due to lack of education and awareness about the virus, most people do not wear mask and gather in large numbers leading to massive rise in infections rates and thereby increasing viral mutations.

Serological survey conducted in December 2020 found that $21 \%$ of population had antibodies meaning they were already infected with COVID-19 compared to $1.8 \%$ cases officially reported. During that time, to estimate the actual number of infections was to multiply officially reported cases by a factor of 26 [25].

\section{B. Lack of Health Care Infrastructure and Man Power}

India tests about 2.03 million people per day in the month of May [26]. India tests $1.35 \%$ per thousand people [24]. The prescribed ration of doctor-patient ration by WHO is $1: 1000$. In India the ratio of allopathic doctor-patient ratio is at $1: 1445$. Considering, native medics practicing ayurveda, unani and homeopathy (AUH), it gives 7.88 lakh doctors in the country. Around which 6.30 lakh doctors practicing traditional systems of medicine were available for service. Thus, taking into account both traditional and allopathic medicine the ratio threw up a doctor patient to $1: 860$ [27]. Traditional medicine also interfered with mindset of people to follow social distancing norms and vaccination [28].

\section{Lack of Preparedness}

A year after the initial coronavirus outbreak many steps could have been takes to prevent and tackle future outbreaks. Testing while simultaneous sending positive samples for genome sequencing of virus could have kept track on mutations. Vaccination which had begun in October of 2020 itself could have been used to vaccinate at least $50 \%$ of population till May of 2021. Ordering for more vaccines candidates instead of relying on only two. Oxygen plants could have been setup in months of February or march as breathlessness and reduces oxygen saturation were always a symptom of COVID-19.

\section{SYMPTOMS}

The new mutant seemed to be undetected initially by current technology of RT-PCR [29]. Yet, patient report abdominal pain, diarrhea, conjunctivitis, bluish discoloration of fingers and toes, rashes, nose bleeding, confusion, brain fog and breathlessness. Apart from usual symptoms of COVID-19 such as, anosmia, aguesia, sore throat, fever, and cough [29].

The incidence of Mucormycossis (Black Fungus) has increased in survivors of COVID-19 [30]. It is caused by species of Rhizopus, Mucor, Absidia. Their spores are found in dust and air. Nearly all patients of Black Fungus are immunocompromised or immunosuppressed. Such patients are those on steroid therapy, received transplantation or have AIDS [30]. Overuse of zinc, steam used for reliving congestion and antibiotic such as azithromycin or doxycycline also leads to increase susceptibility for fungal infection [31]. Cases has also been reported in patient with uncontrolled diabetes [30]. Mucormycossis can be fatal when it invades blood vessels causing thrombus and infarct via lung infection. It leads to loss of eyesight in rhino-cerebral form $[30,32,33]$. The Indian variant of SARS-CoV-2 has spread to Australia, USA, UK, Nepal, Singapore and may other countries [34].

\section{VACCINATION}

The spike protein $(\mathrm{S})$ is the basis for most candidate vaccines, as it mediates virus attachment and entry to host cells and is the target of neutralizing antibody responses [35]. The RNA-dependent RNA polymerase (RdRp) of SARS$\mathrm{CoV}-2$, the main enzyme for viral genome replication has a characteristic feature of proofreading [36, 37]. Therefore, making its rate of mutation appreciably less when compared to other ssRNA viruses such as HIV or Influenza virus.

The two important roles of vaccination are that first, immunize the person against the virus, that is the person should not and would not become COVID positive. Second, since he is not COVID positive, he doesn't have the virus inside his body. Therefore, he acts as a barrier for spread. Due to reduce vaccine effectiveness, single dose vaccinated individual is infected with COVID-19. This decrease in vaccine effectiveness against the new Indian SARS-CoV-2 variants is alarming and worrisome problem. It indicates the need to contain the virus to stop further harmful mutations and development of newer vaccine formulas. Moderna and Pfizer with highest vaccine efficacy also stress the need of third booster dose against new variants across globe. The estimated vaccine effectiveness against B.1.617.2 for a single dose is approximately $33 \%$, for two doses of BNT162b2 is 
approximately $88 \%$ [38]. It is about $66 \%$ for Covishield and $88 \%$ efficacy for Pfizer. [39], [40].

Comparing the severity of symptom of unvaccinated and vaccinated individual getting COVID-19, we find that patients who have received single dose of vaccine have significantly milder symptoms than unvaccinated people. The mortality risk is also less for vaccinated individuals [38].

\section{Steps to Curb Mutants OF VIRUS}

A virus is capable of undergoing replication and mutation only when it is alive. That is when it has infected a host. Therefore, lesser the infection will lessen the chance of virus to grow powerful. The vaccination, although does not provide $100 \%$ protection from virus, limits the effect of disease. Achieving herd immunity natural will not only cost loss of lives but also allow the virus to grow stronger. It may seem an easy way to allow infection to spread rapidly eventually reaching threshold naturally acquired immunity, but it only provides a temporary respite. This is the reason why Sweden which was first country not to impose lockdown in the initial coronavirus wave and tried to achieve herd immunity naturally. It witnessed an overwhelming cases and deaths. Similar to situation India is currently in. Thus, the foremost step to curb the pandemic is to limit the spread of virus. This can be done by imposing lockdown and limiting and restricting movement. We should also educate people about the mechanism of viral mutation so that awareness and sense of responsibility can be instilled. New Zealand and Australia have been able to successful control the pandemic in their country by just limiting movement and educating people regarding effects and spread of virus. Using latest digital technology to help limit spread of virus [41]. In a study that stressed upon the notion of 'digital herd immunity' reports that, in the smartphone era, a population can be immune to epidemics even if not a single one of its members is immune to the disease [41]. This immunity arises because of contacttracing protocols based on smartphone capabilities such as apps which can detect and alert a person about COVID positive persons. It leads to highly efficient quarantining of infected population members and thus the extinguishing of nascent epidemics [41].

Vaccinating the required threshold percentage of people can help to effectively achieve herd immunity without causing damage. Israel has effectively vaccinated more that $60 \%$ of its population achieving herd immunity. It is followed by USA which has also vaccinated about $50 \%$ of its people. Once achieving threshold vaccination number, coronavirus norms such as mask, limited gather, limited travel can all be safely and confidently eased and eventually removed. Rapid and harmful mutation will not only affect its country of origin but also poses a threat to entire world. It even renders the capacity of existing technology of not only vaccines but also the virus detection test such as RT-PCR.

Thus, a country with largest population of world, relying on only two vaccine sources proved to be futile as even after 6 months of first approved vaccines, India has only vaccinated $2 \%$ of its entire population. Extreme vaccine shortage should be followed by prioritizing vaccine to vulnerable groups in the population. Opening it to all 18 years plus age group created havoc which led to crashing of vaccine registration website and long lines at vaccinating center, again violating social distancing norms.

\section{CONCLUSION}

The mismanagement of pandemic gave virus advantage to spread to the large population and undergo three powerful mutations. Counties should adopt to novel technology such as genome sequencing and latest health care infrastructure to control pandemic. Educating and sensitizing of general public about coronavirus also helps to instill responsible behavior.

\section{ACKNOWLEDGEMENT}

I would like to thank Dr. Nusrat Aziz for her valuable knowledge and Fazal Mustafa Ali Khan for his support and guidance.

\section{REFERENCES}

[1] India Population (2021) - Worldometer [Internet]. Worldometers.info. 2021 [cited 5 May 2021]. Available from: https://www.worldometers.info/world-population/indiapopulation/\#: : text=India\%202020\%20population\%20is\%20estimate $\mathrm{d}$,(and\%20dependencies)\%20by\%20population.

[2] Bhadra A, Mukherjee A, Sarkar K. Impact of population density on Covid-19 infected and mortality rate in India. Modeling Earth Systems and Environment. 2020;7(1):623-629.

[3] Park K. Parks Textbook of Preventive and Social Medicine. 25th ed. Margarpatta Road, Pune: M/s Banarsidas Bhanot; 1970.

[4] Gowrisankar A, Rondoni L, Banerjee S. Can India develop herd immunity against COVID-19? The European Physical Journal Plus. 2020 Jun;135(6):1-9.

[5] Coronavirus India lockdown Day 175 updates | September 16, 2020 [Internet]. The Hindu. 2021 [cited 9 May 2021]. Available from: https://www.thehindu.com/news/national/coronavirus-indialockdown-september-16-2020-live-updates/article32617041.ece.

[6] Chakrabarti S, Kaur U, Singh A, Chakrabarti S, Krishnatreya M, Agrawal B et al. Of Cross-immunity, Herd Immunity and Countryspecific Plans: Experiences from COVID-19 in India. Aging and disease. 2020;11(6):1339.

[7] Pringle C. The 20th meeting of the executive committee of the international committee on virus taxonomy. Archives of Virology. 1991;119(3-4):303-304.

[8] Van Regenmortel MH, Ackermann HW, Calisher CH, Dietzgen RG Horzinek MC, Keil GM, Mahy BW, Martelli GP, Murphy FA, Pringle C, Rima BK. Virus species polemics: 14 senior virologists oppose a proposed change to the ICTV definition of virus species. Archives of virology. 2013 May 1;158(5):1115-9.

[9] Ananthanarayan R, Jayaram Paniker C. Textbook of Microbiology 11th ed. Hyderbad: University Press (India) Private Limited; 2021.

[10] Dearlove B, Lewitus E, Bai H, Li Y, Reeves D, Joyce M et al. A SARSCoV-2 vaccine candidate would likely match all currently circulating variants. Proceedings of the National Academy of Sciences. 2020;117(38):23652-23662.

[11] Wang P, Casner R, Nair M, Wang M, Yu J, Cerutti G et al. Increased resistance of SARS-CoV-2 variant P.1 to antibody neutralization. Cell Host \& Microbe. 2021;29(5):747-751.e4.

[12] McCormick KD, Jacobs JL, Mellors JW. The emerging plasticity of SARS-CoV-2. Science. 2021 Mar 26;371(6536):1306-8.

[13] Khatamzas E, Rehn A, Muenchhoff M, Hellmuth J, Gaitzsch E, Weiglein T, Georgi E, Scherer C, Stecher S, Weigert O, Girl P. Emergence of multiple SARS-CoV-2 mutations in an immunocompromised host. medRxiv. 2021 Jan 1.

[14] Baang JH, Smith C, Mirabelli C, Valesano AL, Manthei DM, Bachman MA, Wobus CE, Adams M, Washer L, Martin ET, Lauring AS. Prolonged Severe Acute Respiratory Syndrome Coronavirus 2 Replication in an Immunocompromised Patient. The Journal of infectious diseases. 2021 Jan 1;223(1):23-7.

[15] Frampton D, Rampling T, Cross A, Bailey H, Heaney J, Byott M, Scott $\mathrm{R}$, Sconza R, Price J, Margaritis M, Bergstrom M. Genomic characteristics and clinical effect of the emergent SARS-CoV-2 B. 1.1. 
7 lineage in London, UK: a whole-genome sequencing and hospitalbased cohort study. The Lancet Infectious Diseases. 2021 Apr 12.

[16] Voloch CM, da Silva Francisco R, de Almeida LG, Cardoso CC, Brustolini OJ, Gerber AL, Guimarães AP, Mariani D, da Costa RM, Ferreira OC, Workgroup CU. Genomic characterization of a novel SARS-CoV-2 lineage from Rio de Janeiro, Brazil. Journal of virology. 2021 Apr 26;95(10).

[17] Coronavirus Disease 2019 (COVID-19) [Internet]. Centers for Disease Control and Prevention. 2021 [cited 25 May 2021]. Available from: https://www.cdc.gov/coronavirus/2019-

ncov/variants/variant.html?CDC_AA_refVal=https $\% 3 \mathrm{~A} \% 2 \mathrm{~F} \% 2 \mathrm{Fww}$ w.cdc.gov $\% 2$ Fcoronavirus $\% 2 \mathrm{~F} 2019$ ncov\%2Ftransmission $\% 2$ Fvariant.html.

[18] SARS-CoV-2 variants of concern as of 24 May 2021 [Internet]. European Centre for Disease Prevention and Control. 2021 [cited 25 May 2021]. Available from: https://www.ecdc.europa.eu/en/covid19/variants-concern.

[19] ncov - JHU CSSE [Internet]. Systems.jhu.edu. 2021 [cited 12 May 2021]. Available from: https://systems.jhu.edu/research/publichealth/ncov/.

[20] Coronavirus in the U.S.: Latest Map and Case Count [Internet]. Nytimes.com. 2021 [cited 12 May 2021]. Available from: https://www.nytimes.com/interactive/2021/us/covid-cases.html.

[21] Template: COVID-19 pandemic data - Wikipedia [Internet]. En.wikipedia.org. 2021 [cited 12 May 2021]. Available from: https://en.wikipedia.org/wiki/Template:COVID-19_pandemic_data.

[22] Coronavirus (COVID-19) Vaccinations - Statistics and Research [Internet]. Our World in Data. 2021 [cited 6 May 2021]. Available from: https://ourworldindata.org/covid-vaccinations.

[23] Pandey S. Covid-19 Triple Mutant Virus: Coronavirus triple mutant variant to worsen India's Covid crisis? What we know about 'Bengal strain' - 5 points [Internet]. The Financial Express. 2021 [cited 7 May 2021]. Available from: https://www.financialexpress.com/lifestyle/health/coronavirus-indiatriple-mutant-bengal-covid-strain-latest-news/2238709/.

[24] Coronavirus (COVID-19) Testing - Statistics and Research [Internet]. Our World in Data. 2021 [cited 24 May 2021]. Available from: https://ourworldindata.org/coronavirus-testing.

[25] Sharma N, Sharma P, Basu S, Saxena S, Chawla R, Dushyant K et al. The seroprevalence and trends of SARS-CoV-2 in Delhi, India: A repeated population-based seroepidemiological study. medRixv. 2020

[26] 29. Corona Virus Testing in India | Covid-19 Testing per day - India 330536064 Tests of: total_tested individuals have been done in India so far: total_positive confirmed positive corona cases so far in India CoronaClusters.in [Internet]. Truly Madly. 2021 [cited 24 May 2021] Available from: https://coronaclusters.in/corona-testing-per-day-india.

[27] India P. India's doctor-patient ratio still behind WHO-prescribed 1:1,000: Govt [Internet]. Business-standard.com. 2021 [cited 24 May 2021]. Available from: https://www.business-standard.com/article/ptistories/doctor-patient-ratio-in-india-less-than-who-prescribed-normof-1-1000-govt-119111901421_1.html.

[28] Kakkar K. As I stand in PPE, many patients say drugs don't work, give Coronil - the damage Ramdev did [Internet]. The Print. 2021 [cited 25 May 2021]. Available from: https://theprint.in/opinion/as-i-standin-ppe-many-patients-say-drugs-dont-work-give-coronil-thats-whatramdev-did/663736/.

[29] New coronavirus mutants seem to be undetectable by RTPCR tests: Dr Souradipta Chandra [Internet]. ANI News. 2021 [cited 24 May 2021]. Available from: https://www.aninews.in/news/national/generalnews/new-coronavirus-mutants-seem-to-be-undetectable-by-rtpcrtests-dr-souradipta-chandra20210423211202/.

[30] Ananthanarayan R, Paniker C. Textbook of Microbiology. 11th ed. Hyderabad, Telangana, India: University Press (India) Private Limited; 2021.

[31] Sirur S. Antibiotics, zinc, steam: Kerala doctor wants black fungus cause hunt to go beyond steroids [Internet]. The Print. 2021 [cited 25 May 2021]. Available from: https://theprint.in/health/antibiotics-zincsteam-kerala-doctor-wants-black-fungus-cause-hunt-to-go-beyondsteroids/664066/.

[32] Black fungus detected in Covid-19 survivors, 8 lose eyesight in Surat [Internet]. India Today. 2021 [cited 8 May 2021]. Available from: https://www.indiatoday.in/coronavirus-outbreak/story/black-fungusmucormycosis-detected-covid19-survivors-8-lose-eyesight-suratfungal-infection-symptoms-1799971-2021-05-07.

[33] Srinivasan C. Gujarat Hospital Reports Rise in Covid Cases With Black Fungus Infection [Internet]. NDTV.com. 2021 [cited 8 May 2021] Available from: https://www.ndtv.com/india-news/coronavirus-blackfungal-infection-gujarat-hospital-reports-more-covid-induced-blackfungus-cases-2437714.
[34] Wise J. Covid-19: UK cases of variant from India rise by $160 \%$ in a week BMJ 2021; 373: n1315 doi:10.1136/bmj.n1315.

[35] Dearlove B, Lewitus E, Bai H, Li Y, Reeves D, Joyce M et al. A SARSCoV-2 vaccine candidate would likely match all currently circulating variants. Proceedings of the National Academy of Sciences. 2020;117(38):23652-23662.

[36] Pachetti M, Marini B, Benedetti F, Giudici F, Mauro E, Storici P, Masciovecchio C, Angeletti S, Ciccozzi M, Gallo RC, Zella D. Emerging SARS-CoV-2 mutation hot spots include a novel RNAdependent-RNA polymerase variant. Journal of Translational Medicine. Dec 2020; 18: 1-9.

[37] Khan SF. A review on how exactly covid-19 vaccination works. GSC Biological and Pharmaceutical Sciences. 2021;14(1):075-81.

[38] Jamie Lopez Bernal NA, Charlotte Gower, Eileen Gallagher, Dr Ruth Simmons, Simon Thelwall, Julia Stowe, Elise Tessier, Natalie Groves, Gavin Dabrera, Richard Myers, Vanessa Saliba, Shamez Ladhani, Coli, Campbell, Gayatri Amirthalingam, Matt Edmunds, Maria Zambon, Kevin Brown, Susan Hopkins, Meera Chand, Mary Ramsay. Effectiveness of COVID-19 vaccines against the B.1.617.2 variant 2021 [Available from: https://khub.net/documents/135939561/430986542/Effectiveness+of+ COVID-19+vaccines+against+the+B.1.617.2+variant.pdf/204c11a4e02e-11f2-db19-b3664107ac42.

[39] Covid: Pfizer and AstraZeneca jabs work against Indian variant - study [Internet]. BBC News. 2021 [cited 26 May 2021]. Available from: https://www.bbc.com/news/uk-57214596.

[40] Yadav P, Sapkal GN, Abraham P, Deshpande G, Nyayanit D, Patil DY, Gupta N, Sahay RR, Shete A, Kumar S, Panda S. Neutralization potential of Covishield vaccinated individuals sera against B. 1.617. 1. bioRxiv. 2021 Jan 1.

[41] Bulchandani VB, Shivam S, Moudgalya S, Sondhi SL. Digital herd immunity and COVID-19. Physical Biology. 2021 Apr 7.

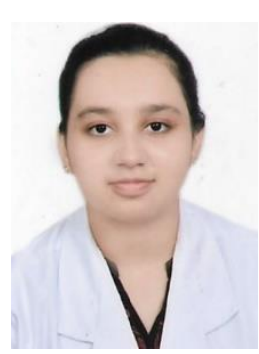

Sheema Fatima Khan is medical student of Shadan Institute of Medical Sciences, Research and Teaching center, Hyderabad, India.

She was also high school topper in International Indian School Jeddah in March 2019.

https://telanganatoday.com/nri-students-in-gulfexcel-cbse-12th-results.

https://saudigazette.com.sa/article/565448.

Her aim is to become a researcher in virology. 